\title{
GM-CSF produced by the airway epithelium is required for sensitization to cockroach allergen
}

\author{
A Sheih ${ }^{1,2}$, WC Parks ${ }^{3}$ and SF Ziegler ${ }^{1,4}$
}

\begin{abstract}
Airway epithelial cells are among the first to encounter inhaled allergens and can initiate allergic responses by producing pro-Th2 innate cytokines. In this study, we investigated the role of epithelial-derived cytokines in sensitization to a clinically relevant allergen, cockroach allergen (CRA). Among the epithelial-derived cytokines, granulocyte macrophage colony-stimulating factor (GM-CSF) had a central role in the initiation of Th2 allergic responses to CRA. We show that initial exposure to CRA directly activated airway epithelial cells through a TLR4-MyD88-dependent pathway and MyD88 signaling in epithelial cells induced upregulation of GM-CSF during sensitization. Epithelial-derived GM-CSF was required for allergic sensitization and selectively restored Th2 responses in the absence of MyD88. Thus, we demonstrate that epithelial-derived GM-CSF is a critical early signal during allergic sensitization to CRA.
\end{abstract}

\section{INTRODUCTION}

Allergic asthma is a chronic lung disease driven by an immune response against allergens, which results in reversible airflow obstruction, mucus hypersecretion, and the recruitment of eosinophils and Th2 cells to the airway. ${ }^{1}$ Airway epithelial cells are among the first to detect the presence of inhaled allergens through pattern recognition receptors, ${ }^{2}$ and in response to allergens, produce cytokines that can initiate type 2 responses. ${ }^{3,4}$ Although transgenic overexpression of epithelial-derived cytokines such as thymic stromal lymphopoietin (TSLP), IL-25, IL-33, and granulocyte macrophage colonystimulating factor (GM-CSF) are each sufficient to induce a Th2 allergic response against an antigen, ${ }^{5-8}$ mounting evidence suggests that the requirement for these cytokines in allergic responses to various allergens is distinct.

TSLP is induced in a large number of allergic responses ${ }^{9-14}$ and is required in ragweed-driven allergic inflammation. Yet TSLP has been shown to be dispensable for allergic sensitization to house dust mite (HDM), in which IL-33 appears to have a more central role. ${ }^{10,15}$ GM-CSF, which can be produced by a number of different cell types including epithelial cells, has also emerged as an important regulator of allergic inflammation. ${ }^{15}$ Patients with asthma have increased levels of GM-CSF expression; in mice, transgenic overexpression of GM-CSF serves as a potent adjuvant that permits sensitization to ovalbumin $^{8}$ and sub-threshold levels of HDM. ${ }^{16}$ Antibody blockade of GM-CSF during sensitization reduces allergic inflammation to HDM and Blomia tropicalis mite allergen, ${ }^{15,17,18}$ suggesting an important role for GM-CSF early in the allergic response.

In this study, we focus on cockroach allergen (CRA), an important allergen associated with allergic asthma and asthma morbidity, especially in low-income urban populations. ${ }^{19-21}$ CRA can activate protease-activated receptor 2 (PAR2) $)^{22-24}$ and toll-like receptors (TLRs) ${ }^{25}$ to induce the release of inflammatory cytokines. However, TSLP is not required for allergic responses to CRA, ${ }^{26}$ whereas IL-25 is only required for chronic allergic responses to $\mathrm{CRA}^{27}$ Our studies demonstrate that MyD88dependent induction of GM-CSF in epithelial cells was required for sensitization to inhaled CRA. Epithelial-derived GM-CSF specifically promoted Th2-mediated allergic responses, but not Th17-associated neutrophilia, downstream of the MyD88signaling pathway. Interestingly, although induction of GMCSF has been shown to occur downstream of IL-1 in response to HDM, CRA-induced GM-CSF was IL-1 independent. In contrast to the requirements for IL-33 in HDM-induced asthma, IL-33 only had a minimal role in response to CRA. Overall, our study demonstrates that epithelial-derived GM-CSF is a key mediator of sensitization to CRA, but that induction of GM-CSF by CRA is mediated by pathways distinct from HDM.

${ }^{1}$ Immunology Program, Benaroya Research Institute at Virginia Mason, Seattle, WA, USA. ${ }^{2}$ Molecular and Cellular Biology Program, University of Washington, Seattle, WA, USA. ${ }^{3}$ Department of Medicine (Pulmonary and Critical Care Medicine, Cedars-Sinai Medical Center, Los Angeles, CA, USA and ${ }^{4}$ Department of Immunology, University of Washington School of Medicine, Seattle, WA, USA. Correspondence: SF Ziegler (sziegler@benaroyaresearch.org) 


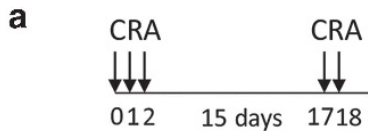

b

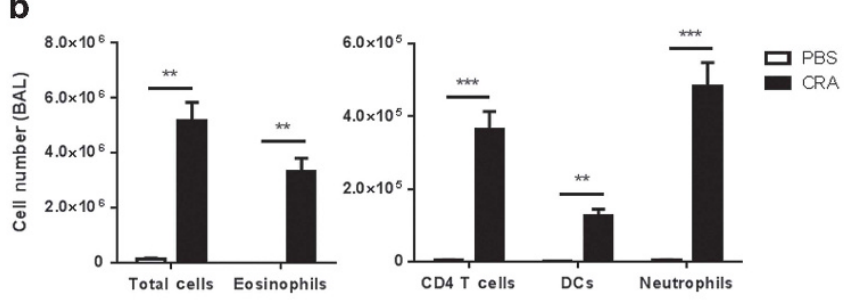

C
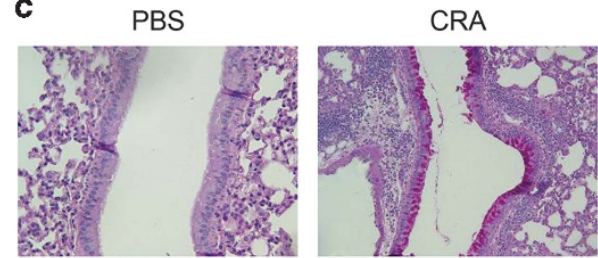

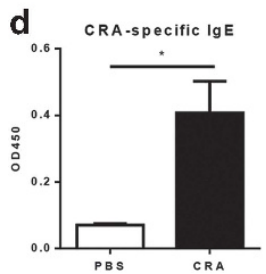

e
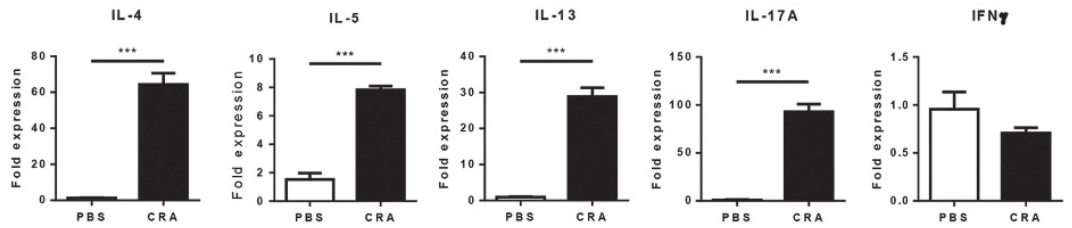

Figure 1 Intranasal sensitization and challenge with CRA results in airway inflammation with features of allergic asthma. (a) On days 0-2, C57BL/6 mice were intranasally sensitized with CRA and challenged with CRA on days 17-18. Allergic airway inflammation was assessed $72 \mathrm{~h}$ after the last challenge. (b) BAL differential cell counts were determined by flow cytometry. (c) PAS staining of formalin-fixed and paraffin-embedded lung sections. PAS-positive cells (purple) represent mucus-producing goblet cells. Original magnification, $\times 40$. (d) Serum levels of CRA-specific IgE were determined by ELISA. (e) RNA was isolated from the lungs of PBS-versus CRA-challenged mice and mRNA expression of IL-4, IL-5, IL-13, IL-17A, and IFN $\gamma$ was determined by qPCR. All expression values are relative to PBS control samples and normalized to the housekeeping gene GAPDH. Data represent mean \pm s.e.m. ( $n=4-8$ mice per group). Comparisons were made using unpaired Student's $t$-test. ${ }^{\star} P<0.05,{ }^{\star *} P<0.01,{ }^{* \star \star} P<0.001$.

\section{RESULTS}

Intranasal sensitization and challenge with CRA results in airway inflammation with features of allergic asthma

We first established a model of CRA-mediated allergic airway disease in which mice were sensitized and challenged with the allergen in the absence of an adjuvant (Figure 1a). Following CRA challenge, mice developed airway inflammation with eosinophils representing the main infiltrating cell type (Figure 1b). There was also a significant increase in the recruitment of CD4 T cells, DCs, and neutrophils to the airway (Figure 1b). Consistent with an allergic response, histological analysis of lung sections showed extensive goblet cell metaplasia and mucus production (Figure 1c). In addition, we detected elevated levels of CRA-specific IgE antibodies in the serum (Figure 1d) as well as increased lung mRNA expression of $\mathrm{T}_{\mathrm{H}} 2$ and $\mathrm{T}_{\mathrm{H}} 17$ cytokines, with no effect on IFN $\gamma$ (Figure 1e). Depletion of CD4 T cells prior to sensitization and challenge protected mice from the development of allergic inflammation in response to CRA (Supplementary Figure 1 online). These results show that sensitization and challenge with CRA leads to the development of airway inflammation that closely resembles allergic asthma.

\section{MyD88 is required for the development of allergic airway} inflammation to CRA

A previous study showed that MyD88 is required in bone marrow (BM)-derived DCs for production of IL-6 and IL-23 after exposure to CRA, but it is unknown if MyD88 is required for allergic responses to CRA. ${ }^{25} \mathrm{Myd} 88-/-$ mice sensitized and challenged with CRA developed markedly less airway inflammation compared with wild-type (WT) mice; the number of eosinophils, neutrophils, and CD4 T cells were strongly reduced in the bronchoalveolar lavage (BAL) (Figure 2a). Histological analysis confirmed this reduction in immune cell infiltrates and revealed less mucus production in the lung (Figure 2b). Furthermore, both $\mathrm{T}_{\mathrm{H}} 2$ and $\mathrm{T}_{\mathrm{H}} 17$ cytokine levels were significantly lower in the BAL fluid of Myd88-/- mice (Figure 2c). These results reveal an important role for the MyD88 signaling pathway in the development of allergic airway inflammation to CRA.

Next, we investigated the role of individual TLRs in sensing CRA and found no significant differences in airway eosinophilia between WT and Tlr2-/- mice (Supplementary Figure 2a). In contrast, TLR4-deficient mice exhibited significantly reduced airway eosinophilia, mucus production, and $\mathrm{T}_{\mathrm{H}} 2$ cytokine production (Supplementary Figure 2b-d). Because lipopolysaccharide (LPS) is a TLR4 agonist that can promote $\mathrm{T}_{\mathrm{H}} 2$ responses at low doses, ${ }^{28}$ we measured the concentration of contaminating LPS in CRA. We found that each dose of CRA contained 11 ng of LPS (data not shown) and asked if this low level of LPS was sufficient to drive sensitization to an antigen. In contrast to CRA-treated mice, mice sensitized and challenged with $11 \mathrm{ng}$ of LPS plus ovalbumin failed to develop airway eosinophilia (Supplementary Figure 3). This suggests that, while LPS might contribute, it alone does not drive sensitization to CRA.

In addition to TLRs, MyD88 is also required for signaling pathways downstream of the IL-1 receptor family. Members of 


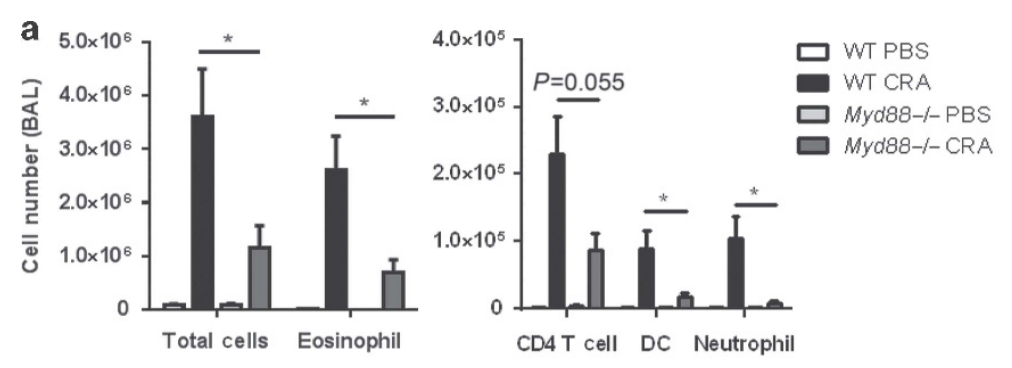

b

C57BL/6
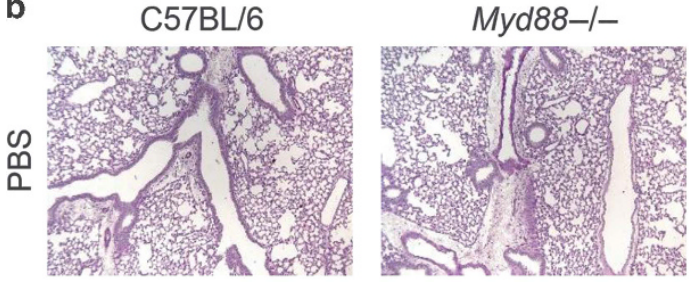

c
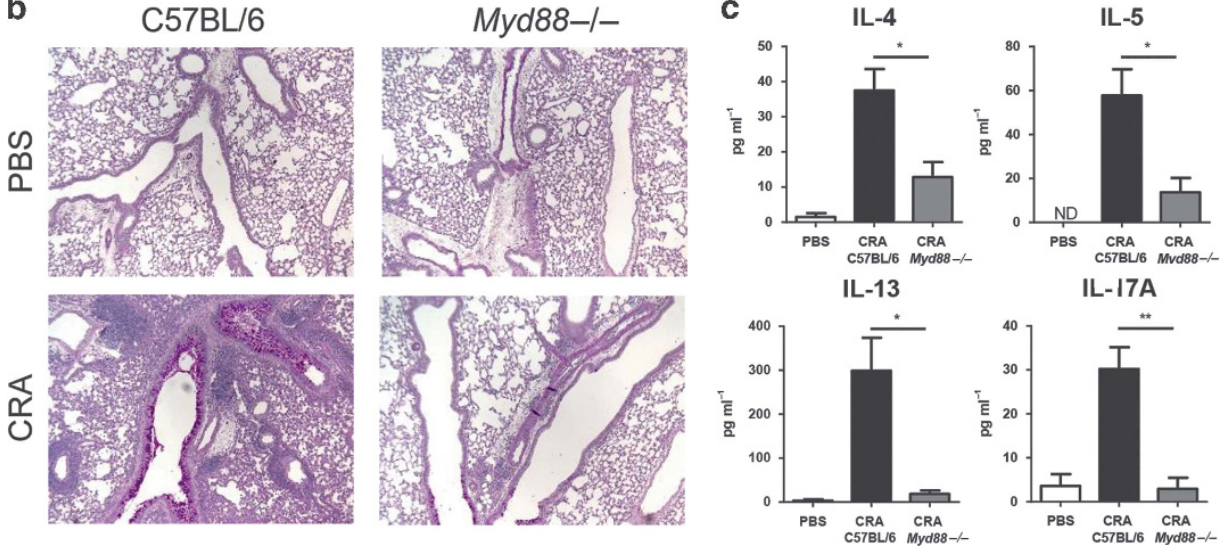

Figure 2 MyD88 is required for the development of allergic airway inflammation to CRA. C57BL/6 and Myd88-/ - mice were sensitized and challenged with CRA as described in the Methods. (a) BAL differential cell counts were determined by flow cytometry $72 \mathrm{~h}$ after the last challenge. (b) PAS staining of formalin-fixed and paraffin-embedded lung sections. Original magnification, $\times 10$. (c) Concentration of IL-4, IL-5, IL-13, and IL-17A from BAL fluid was determined by ELISA. Data represent combined data of two independent experiments, mean \pm s.e.m. ( $n=4-9$ mice per group). Comparisons were made using unpaired Student's $t$-test. ${ }^{*} P<0.05,{ }^{* \star} P<0.01$.

the IL- 1 cytokine family, such as IL- $1 \alpha$ and IL-33, have been shown to be important for sensitization to HDM. ${ }^{15}$ When IL1R signaling was blocked with anakinra, an IL-1 receptor antagonist, levels of airway eosinophilia were similar to that of the control group (Supplementary Figure 4a). These results demonstrate that IL- $1 \alpha$ and IL1 $\beta$ are not required for allergic response to CRA. Consistent with this data, we also found that IL- $1 \propto$ was not upregulated in response to low or high dose of CRA (data not shown). Next, we compared WT and casp1 - / mice to determine the role of IL-18 and IL-1 $\beta$. Caspase 1 is required for processing pro-IL-1 $\beta$ and pro-IL-18 into their active forms. Again, we found no significant differences in eosinophil numbers between WT and casp1-/ - mice after CRA challenge (Supplementary Figure 4b). However, when IL-33-deficient mice were sensitized and challenged with CRA, there was a significant decrease in airway eosinophilia compared with WT mice. Surprisingly, the numbers of CD4 T cells, DCs, and neutrophils remained elevated in IL-33-deficient mice (Supplementary Figure 4c). These results show that among the IL-1 cytokines, IL-33 had a limited role in CRA-induced airway eosinophilia.

\section{MyD88 is required in lung epithelial cells for allergic inflammation to CRA}

MyD88 is expressed broadly in both immune and structural cells. To determine which of these cellular compartments were responsible for MyD88-dependent responses to CRA, we established reciprocal BM chimeras in which WT or Myd88 - / - BM cells were transferred into irradiated WT or Myd88 - / - hosts. WT $\rightarrow$ WT BM chimeric mice developed a robust allergic response to CRA. In contrast, $M y d 88-I-\rightarrow$ Myd88 - / - BM chimeric mice developed reduced eosinophilia, which confirmed the critical role of MyD88 in CRAinduced allergic inflammation (Supplementary Figure 5). A similar reduction in eosinophilia was observed when MyD88 was absent in structural cells (WT $\rightarrow M y d 88-/-$ ). In contrast, absence of MyD88 in the radiosensitive, hematopoietic compartment (Myd88-/ $\rightarrow$ WT) did not affect the degree of allergic inflammation to CRA (Supplementary Figure 5). These results indicate that MyD88 expression is required in lung radioresistant cells for a $\mathrm{T}_{\mathrm{H}} 2$ allergic response against CRA.

MyD88 is expressed by various structural cells in the lung such as epithelial cells and fibroblasts. ${ }^{29}$ Because epithelial cells are uniquely positioned to sense inhaled allergens and can initiate $\mathrm{T}_{\mathrm{H}} 2$ allergic responses, we hypothesized that MyD88 expression is required in epithelial cells to promote sensitization to CRA. To test this hypothesis, we generated mice that lacked MyD88 specifically in lung epithelial cells by crossing $M y d 88^{f l / f l}$ mice with mice expressing Cre recombinase under the control of the $3.7-\mathrm{kb}$ human surfactant protein $\mathrm{C}$ (SPC) promoter. $^{30,31}$ The SPC promoter is expressed in the primary lung buds starting at E10.5 and directs recombination in all airway and alveolar epithelial cells. ${ }^{30,32-34}$ When SPC-Cre/ 
$M y d 88^{f l f l}$ mice were sensitized and challenged with CRA, they developed significantly reduced airway eosinophilia and goblet cell metaplasia (Figure 3a and $\mathbf{b}$ ). In addition, restimulation of cells isolated from the lungs of these mice revealed a significant decrease in the percentage and number of $\mathrm{IL}-5^{+}$and IL- $13^{+}$ CD4 T cells (Figure 3c). On the other hand, deletion of MyD88 in CD11c + cells and CD4 T cells had no effect on the degree of airway inflammation following sensitization and challenge with CRA (Supplementary Figure 6). Altogether, these results demonstrate that MyD88 signaling in lung epithelial cells, but not hematopoietic cells, is important for initiation of allergic responses against CRA.

\section{GM-CSF is produced by lung epithelial cells in a MyD88-dependent manner}

Following allergen exposure, epithelial cells can initiate and regulate $\mathrm{T}_{\mathrm{H}} 2$ responses through production of prototypical cytokines such as TSLP, IL-25, and IL-33. ${ }^{2}$ However, we found
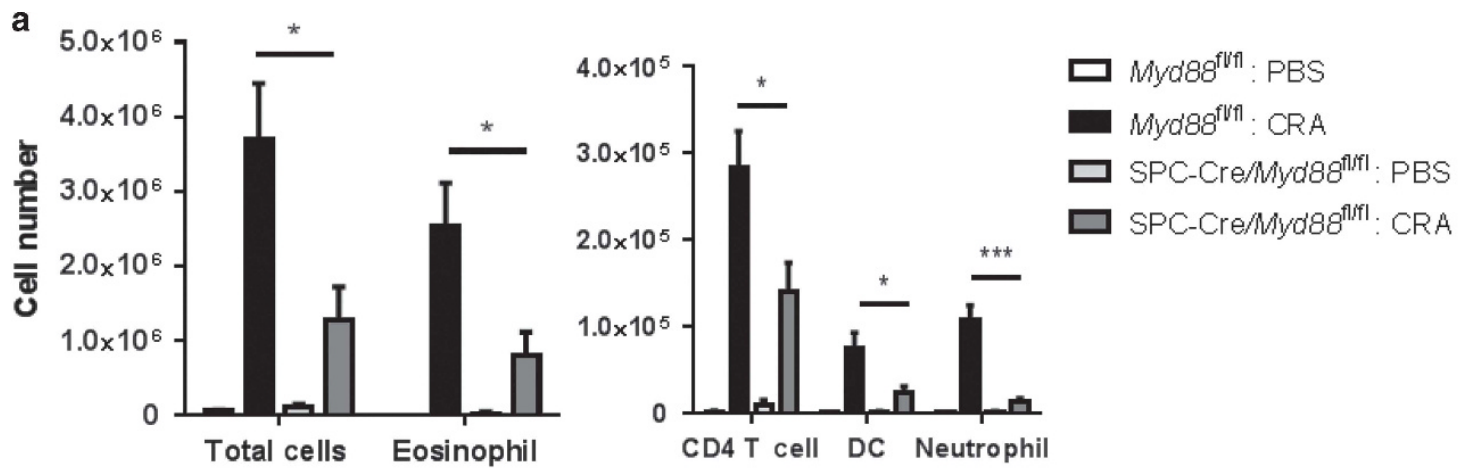

b
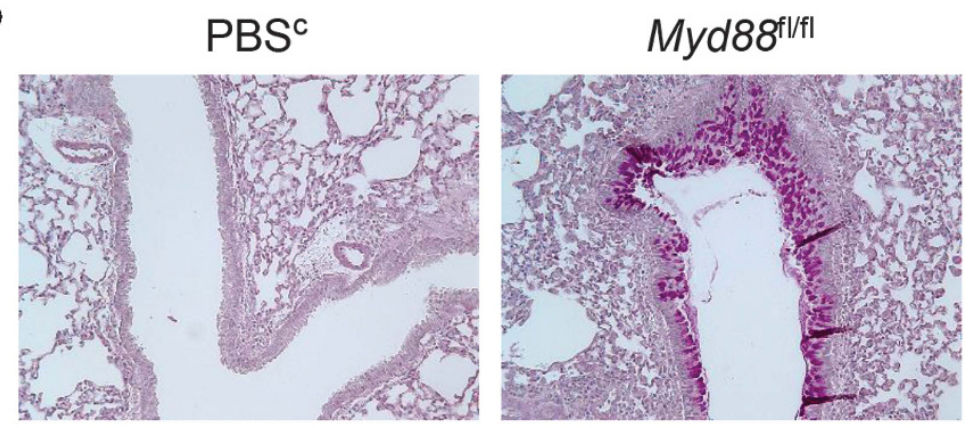

SPC-Cre/Myd88f/ff

C
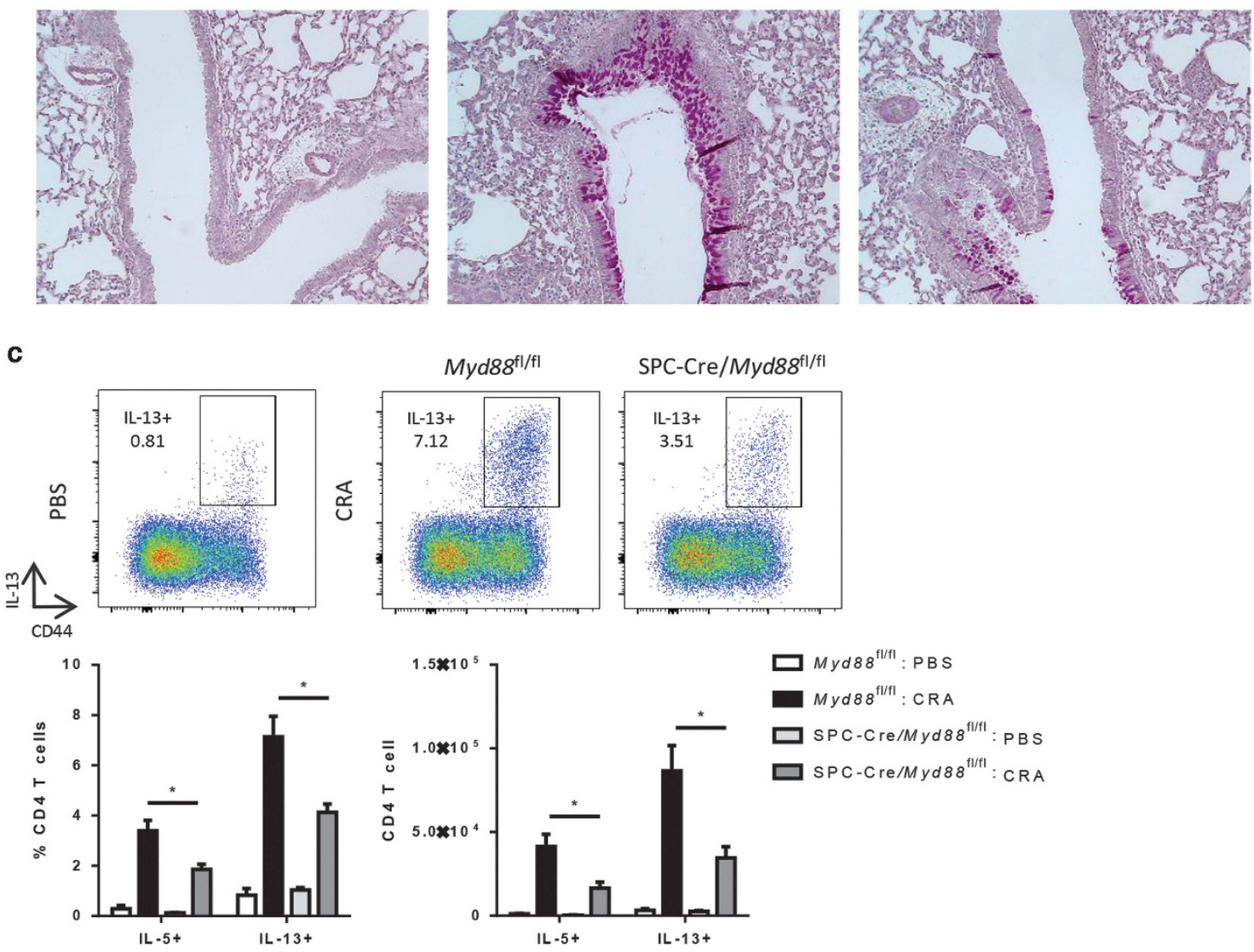

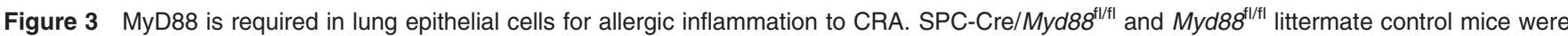
sensitized and challenged with CRA. (a) BAL cell differentials were determined by flow cytometry. (b) PAS staining of formalin-fixed and paraffinembedded lung sections. Original magnification, $\times 20$. (c) Percent and number of lung CD4 T cells positive for IL-5 and IL-13 after restimulation with PMA and ionomycin. Data represent combined data of two independent experiments, mean \pm s.e.m. ( $n=4-9$ mice per group). Comparisons were made using unpaired Student's $t$-test. ${ }^{*} P<0.05,{ }^{* *} P<0.01$. 


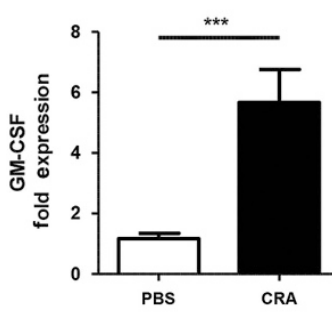

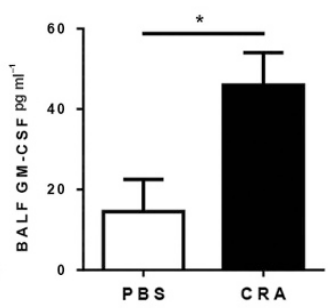

b

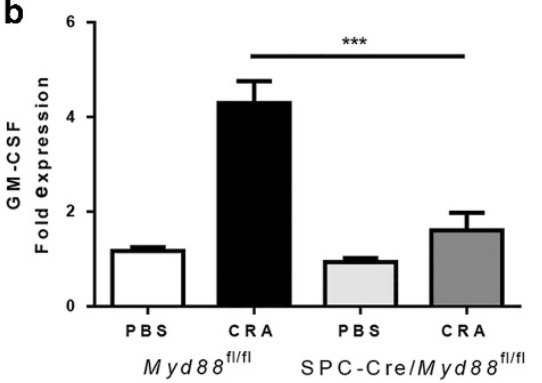

C

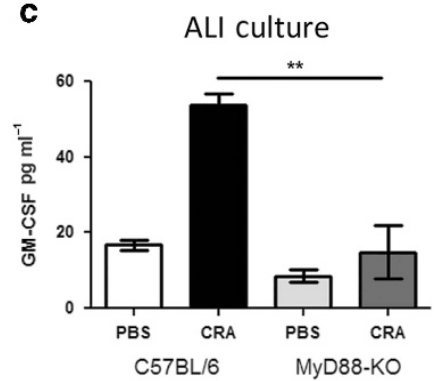

Figure 4 GM-CSF is produced by lung epithelial cells in a MyD88-dependent manner. (a) C57BL/6 mice were intranasally treated with CRA. Two hours later, lung tissue was collected and mRNA expression of GM-CSF was determined by qPCR. Expression values are relative to PBS control samples and normalized to the housekeeping gene GAPDH. BAL fluid was also collected and GM-CSF protein level was measured by ELISA. Data represent combined data of two independent experiments, mean \pm s.e.m. ( $n=7-15$ mice per group). (b) SPC-Cre/Myd8 $8^{f / / f l}$ and $M y d 88^{f / / 1 / 1}$ mice were intranasally treated with CRA. Two hours later, lung tissue was collected and mRNA expression of GM-CSF was determined by qPCR. Data represent combined data of two independent experiments, mean \pm s.e.m. ( $n=4-10$ mice per group). (c) Tracheas from C57BL/6 and Myd88-/ - mice were harvested and primary epithelial cells were cultured at air-liquid interface. Cells were exposed to $15 \mu \mathrm{g}$ of CRA or PBS for $24 \mathrm{~h}$ and medium from the basal compartment was collected. GM-CSF levels were measured by ELISA. Data represent mean \pm s.e.m. of one experiment and are representative of two independent experiments. Comparisons were made using unpaired Student's $t$-test. ${ }^{*} P<0.05,{ }^{\star \star} P<0.01,{ }^{\star \star \star} P<0.001$.

no significant differences in CRA-induced airway eosinophilia between WT, Tslp-/-, and Ill7rb-/- mice (Supplementary Figure 7), whereas IL-33-deficient mice only displayed a reduction in eosinophilia (Supplementary Figure 4c).

When we examined additional epithelial-derived cytokines induced by CRA, we found elevated levels of GM-CSF in the BAL as early as $2 \mathrm{~h}$ post sensitization (Figure $4 a$ ). To assess if upregulation of GM-CSF was dependent on MyD88 signaling in lung epithelial cells, we analyzed the expression of GM-CSF in SPC-Cre/Myd88 $8^{\text {fl/fl }}$ mice after sensitization with CRA. SPC-Cre/Myd88 $8^{f l f l}$ mice failed to upregulate GM-CSF in response to CRA, suggesting that MyD88 signaling in lung epithelial cells triggers the release of GM-CSF (Figure $4 \mathbf{b}$ ).

To confirm that epithelial cells produced GM-CSF in response to CRA, we established organotypic air-liquid interface (ALI) cultures of primary epithelial cells from WT and Myd88-/ - tracheas. When WT ALI cultures were stimulated with CRA, there was a significant increase in GM-CSF levels in the culture medium on the basolateral side (Figure 4c). In contrast, ALI cultures established from Myd88-/ - mice failed to upregulate GM-CSF after stimulation with CRA (Figure 4c). Altogether, these results demonstrate that airway epithelial cells produce GM-CSF in a MyD88-dependent manner following exposure to CRA.

\section{GM-CSF is required during allergic sensitization, but not challenge, in CRA-driven allergic airway disease}

To investigate the role of epithelial-derived GM-CSF in regulating CRA-driven allergic airway disease, mice were treated with a neutralizing $\alpha \mathrm{GM}$-CSF antibody at either sensitization or challenge. Blocking GM-CSF at sensitization strongly reduced airway inflammation after CRA challenge, with eosinophil numbers in the BAL significantly lower compared with isotype control treatment (Figure 5a). There was also a reduction in the number of CD4 T cells,
DCs, and neutrophils (Figure 5a). Furthermore, mRNA expression of type 2 cytokines and serum CRA-specific IgE levels were also significantly reduced (Figure $\mathbf{5 c}$ and $\mathbf{d}$ ). In contrast, blocking GM-CSF at challenge failed to reduce airway eosinophilia in mice sensitized and challenged with CRA (Figure 5e). These results reveal a crucial role for GM-CSF during sensitization, but not challenge, in CRA-induced allergic airway disease.

\section{GM-CSF is required for optimal dendritic cell function and Th2 priming}

Given that the allergic response to CRA is CD4 T cell driven, we postulated that GM-CSF had a role in DC function during priming. To explore this possibility, we asked how neutralization of GM-CSF affected the maturation of DCs after exposure to CRA. Mice were sensitized with fluorescently labeled CRA in the presence or absence of the $\alpha \mathrm{GM}$-CSF antibody, and the number of $\mathrm{CRA}^{+}$DCs in the draining lymph node was determined by flow cytometry. Neutralization of GM-CSF significantly reduced the delivery of fluorescently labeled CRA to the draining lymph node. There was a reduction in both the percentage and total number of A647-CRA ${ }^{+}$DCs in the lungdraining lymph node $24 \mathrm{~h}$ after CRA administration (Figure 6a). In addition, surface expression of the costimulatory molecule CD80 was markedly decreased on A $647^{+}$DCs (Figure 6b). These findings suggest that GM-CSF regulates the ability of DCs to acquire antigen, upregulate costimulatory molecules, and migrate to the draining lymph node during sensitization. To examine if GM-CSF blockade affected the ability of DCs to prime $\mathrm{T}_{\mathrm{H}} 2$ cells, we sensitized mice with CRA and collected lung-draining lymph node cells on day 3 . When these cells were restimulated with CRA, there was a significant reduction in the production of $\mathrm{T}_{\mathrm{H}} 2$ cytokines from $\alpha \mathrm{GM}$-CSF-treated mice (Figure 6c). Overall, these results demonstrate that GM-CSF is required for optimal function of DCs and Th2 priming during CRA sensitization. 
a

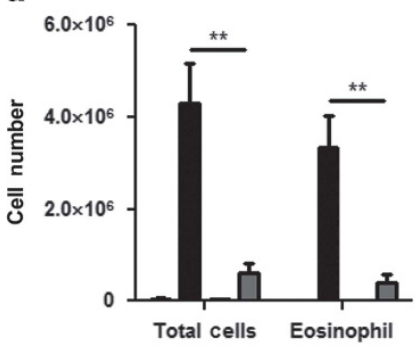

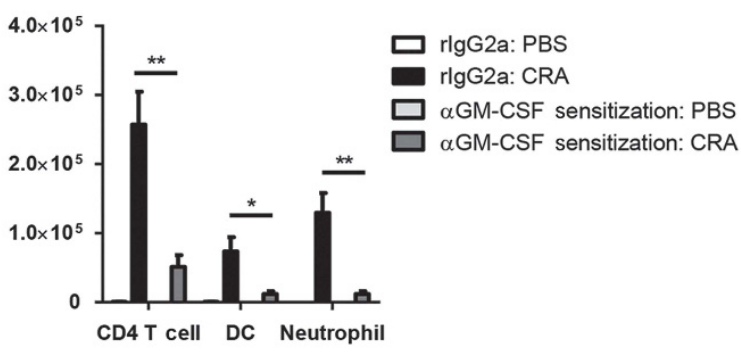

C

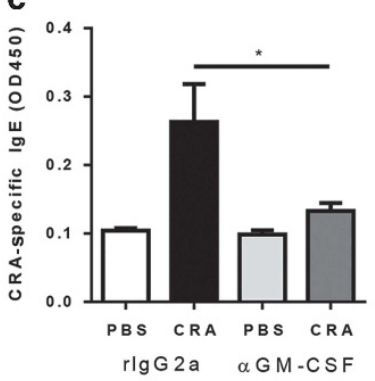

b

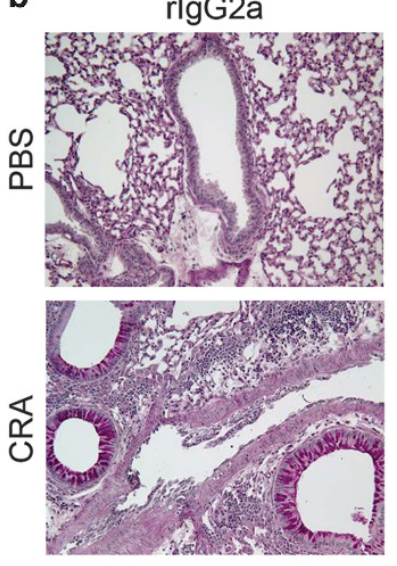

aGM-CSF

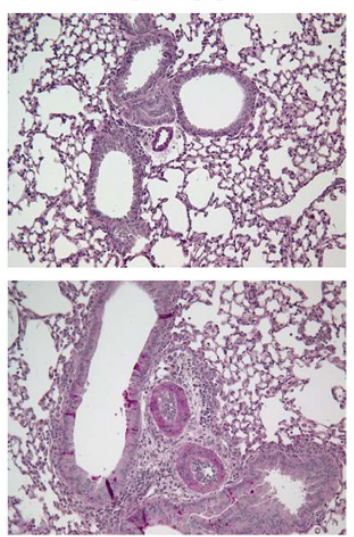

d
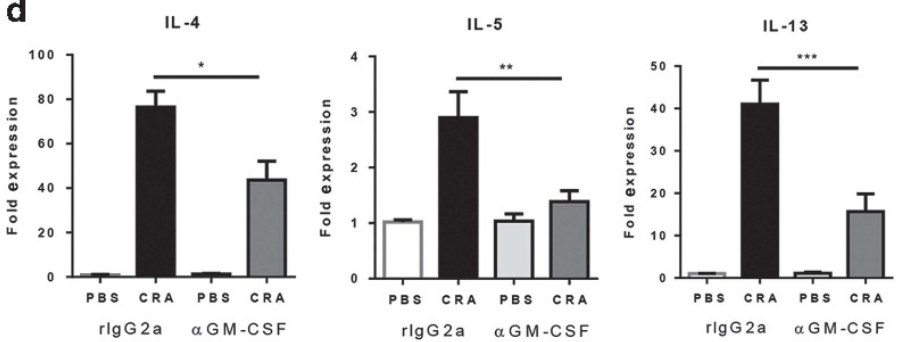

e

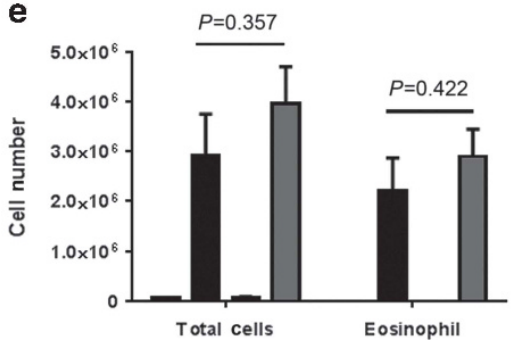

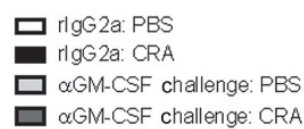

Figure 5 GM-CSF is required during allergic sensitization, but not challenge, in CRA-driven allergic airway disease. C57BL/6 mice were treated with rlgG2a or a neutralizing anti-GM-CSF antibody, $5 \mathrm{~h}$ prior to sensitization. Mice were then sensitized and challenged with CRA and airway inflammation was analyzed $72 \mathrm{~h}$ later. (a) BAL differential cell counts were determined by flow cytometry. (b) PAS staining of formalin-fixed and paraffin-embedded lung sections. Original magnification, $\times 20$. (c) Serum levels of CRA-specific IgE. (d) RNA was isolated from the lung and mRNA expression of IL-4, IL-5, and IL-13 was determined by GPCR. All expression values are relative to PBS control samples and normalized to the housekeeping gene GAPDH. Data represent combined data of two independent experiments, mean \pm s.e.m. ( $n=3-10$ mice per group). (e) C57BL/6 mice were treated with rlgG2a or a neutralizing anti-GM-CSF antibody, $5 \mathrm{~h}$ prior to challenge. After allergen challenge, BAL differential cell counts were determined by flow cytometry. Data represent combined data of two independent experiments, mean \pm s.e.m. ( $n=5-9$ mice per group). Comparisons were made using unpaired Student's t-test. ${ }^{*} P<0.05,{ }^{* *} P<0.01,{ }^{* * *} P<0.001$.

\section{GM-CSF selectively rescues $T_{\mathrm{H}} 2$ allergic airway response to CRA in Myd88 - $I-$ mice}

To determine the function of GM-CSF downstream of MyD88 signaling, GM-CSF was administered intranasally to Myd88 - / - mice during CRA sensitization. Treatment with GM-CSF largely restored airway inflammation in Myd88 - / mice to levels observed in WT mice. This was due to a significant increase in the number of eosinophils and CD4 T cells, whereas recruitment of neutrophils to the BAL was not recovered by GM-CSF treatment (Figure $7 \mathbf{a}$ and b). Furthermore, GM-CSF selectively restored $\mathrm{T}_{\mathrm{H}} 2$, but not $\mathrm{T}_{\mathrm{H}} 17$ responses, in $M y d 88-/-$ mice. In vitro restimulation of lung cells with PMA/ionomycin revealed a significant increase in the number of IL- $5^{+}$and IL- $13^{+} \mathrm{CD} 4 \mathrm{~T}$ cells, but not IL-17A ${ }^{+}$or IFN $\gamma^{+}$CD4 T cells (Figure 7d). Consistent with the recovery of $\mathrm{T}_{\mathrm{H}} 2$ responses, CRA-specific IgE levels were also restored by GM-CSF treatment (Figure 7c). These results demonstrate that epithelial-derived GM-CSF specifically promotes $\mathrm{T}_{\mathrm{H}} 2$-mediated eosinophilic inflammation following exposure to CRA.

\section{DISCUSSION}

The airway epithelium coordinates allergic responses by producing pro-Th2 cytokines such as TSLP, IL-25, IL-33, and GM-CSF. Although studies using HDM allergen have provided valuable insights into the role of epithelial-derived cytokines in mucosal sensitization, understanding pathways of sensitization initiated by other clinically relevant allergens remain important given that allergens are structurally and functionally distinct. Here, we focused on CRA, an important factor in the development of asthma for inner-city children. We uncovered a critical role for epithelial-derived GM-CSF in allergic sensitization to CRA, in which GM-CSF specifically promoted Th2 priming by regulating the functional maturation of DCs. Interestingly, although IL- $1 \alpha$ initiates the release of 

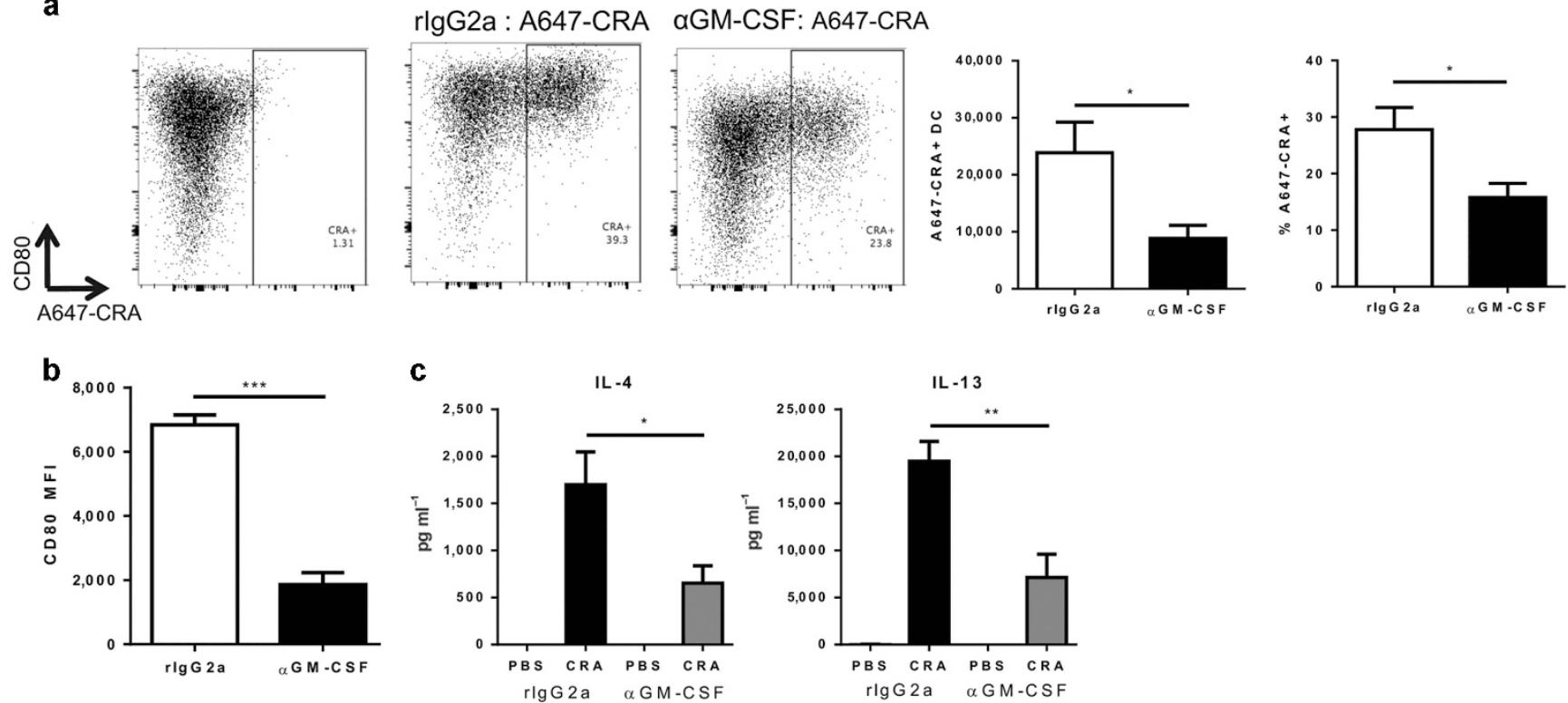

Figure 6 GM-CSF is required for optimal dendritic cell function and Th2-priming. C57BL/6 mice were treated with rlgG2a or a neutralizing anti-GM-CSF antibody, $5 \mathrm{~h}$ prior to intranasal administration with A647-CRA. The draining lymph node was collected $24 \mathrm{~h}$ later and cells were analyzed by flow cytometry to assess the uptake of CRA and maturation of DCs. DCs were gated as CD11c + and MHCII + . (a) Total number of A647 + DCs and percent of A647 + DCs within the DC population. (b) Mean fluorescent intensity (MFI) of costimulatory molecule CD80 on A647 + DCs. Data represent combined data of two independent experiments, mean \pm s.e.m. ( $n=9$ mice per group). (c) On days $0-2$, C57BL/6 mice were sensitized with CRA. On day 3 , the lung draining lymph node was collected and cells were restimulated with CRA. On day 7, culture supernatant was collected and concentration of IL-4 and IL-13 were determined by ELISA. Data represent mean \pm s.e.m. of one experiment $(n=3-5$ mice per group) and are representative of two independent experiments. Comparisons were made using unpaired Student's $t$-test. ${ }^{*} P<0.05,{ }^{* \star} P<0.01$, ${ }^{* \star *} P<0.001$.

GM-CSF in response to HDM, IL- $1 \alpha$ was not required for CRA-induced GM-CSF. In addition, IL-33 only had a minor role in allergic response to CRA, whereas IL-33 is critical for allergic sensitization to HDM. Thus, our study demonstrates that epithelial-derived GM-CSF is a critical early signal for the initiation of Th2 allergic responses to CRA.

Activation of PAR2 by CRA-derived proteases is important for initiation of allergic responses to CRA. However, in the absence of PAR2, allergic response to CRA is partially reduced but nonetheless intact, which suggests a role for other pattern recognition receptors in the recognition of CRA. ${ }^{35}$ In this study, we have identified TLR4-MyD88 as a major signaling pathway that promotes sensitization to CRA. We show that MyD88 signaling was required in lung epithelial cells for upregulation of GM-CSF during sensitization. Previous studies have shown that CRA-derived proteases can also induce GMCSF production by epithelial cells through a PAR2-dependent mechanism. ${ }^{36}$ Our findings suggest that in addition to PAR2, TLR4-MyD88 signaling pathway is another important signaling pathway that mediates production of GM-CSF in response to CRA.

TLR4 stimulation with a low dose of LPS can promote Th2 responses to inhaled antigens. ${ }^{28}$ Here we show that the TLR4mediated response to CRA extends beyond an immune response to LPS and antigen since the low level of contaminating LPS in CRA was not sufficient to induce Th2 allergic responses. Instead, it is possible that other components of CRA or the release of endogenous ligands mediates this
TLR4-dependent response to CRA. Bla g 1, a major CRA, contains a hydrophobic cavity that binds to lipids known to activate TLR4. ${ }^{37}$ Therefore, Bla g 1 may lower the threshold of LPS needed to generate a $\mathrm{T}_{\mathrm{H}} 2$ allergic response by enhancing TLR4 binding. Alternatively, TLR4 may be activated by an endogenous ligand released in response to CRA such as high mobility group box $1 .{ }^{38}$ This ability to trigger TLR4 is a characteristic shared by many allergens, and our findings further support the idea that TLR4 signaling is essential for the development of allergic inflammation.

Previous studies have shown that CRA contains a TLR2 agonist. ${ }^{39}$ However, we found that TLR2 was not required for allergic responses to CRA. This finding is consistent with a study by Page et al. ${ }^{40}$ in which TLR $2-/-$ mice displayed increased airway inflammation against CRA. Although we did not find a protective role for TLR2, which could be due to differences in the route of sensitization and administration protocol, our data demonstrates that TLR2 is not required for allergic sensitization to CRA.

Activation of airway epithelial cells is a critical first step in the initiation of responses to aeroallergens. In this study, we demonstrate that MyD88 expression in radioresistant cells was necessary and sufficient for allergic airway response to CRA. Furthermore, we determined that MyD88 signaling in lung epithelial cells, but not in CD11c + alveolar macrophages or DCs, was required for sensitization to CRA. Our findings indicate that MyD88 signaling in epithelial cells has a predominant role in facilitating allergic responses to CRA. 

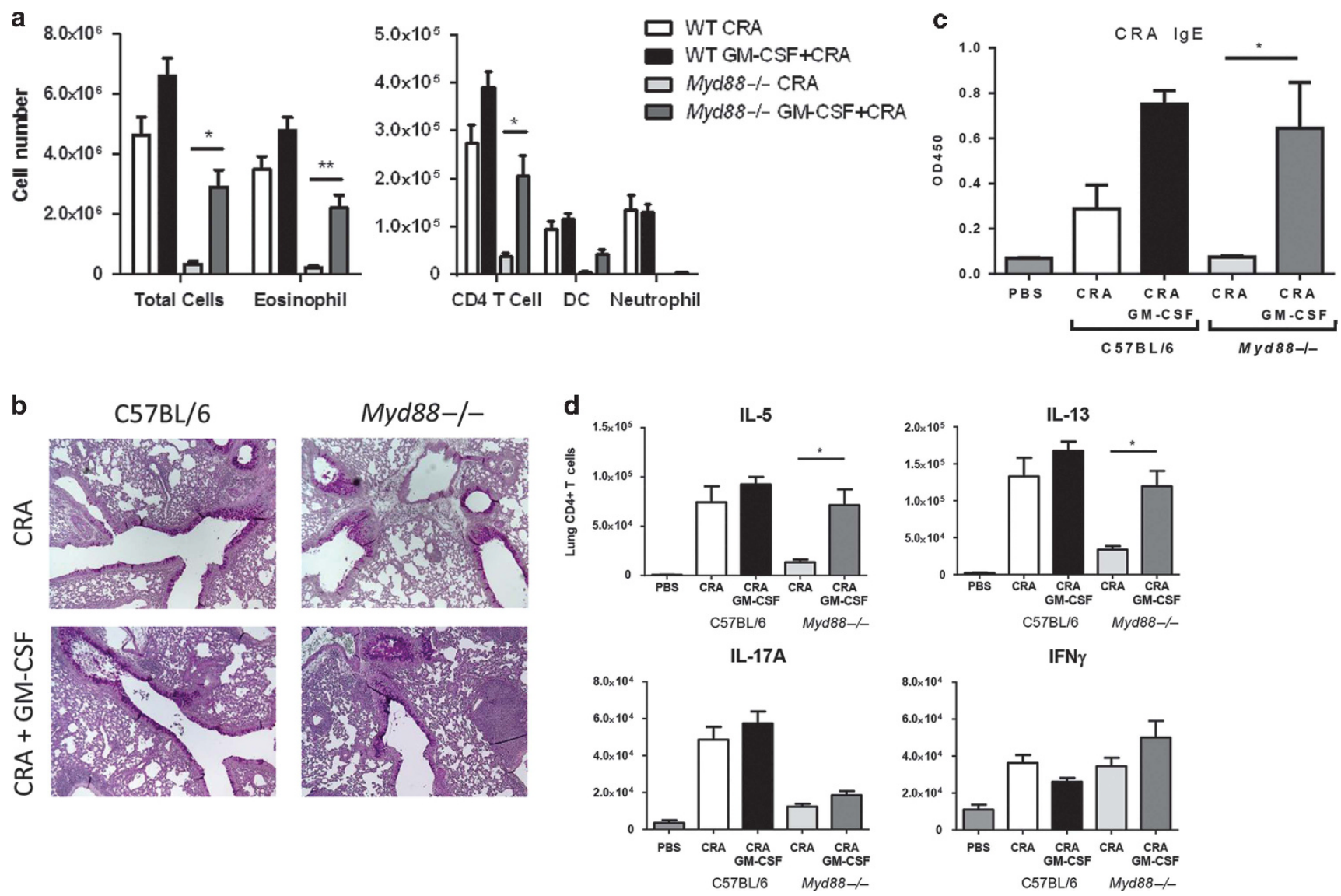

Figure 7 GM-CSF selectively rescues $\mathrm{T}_{\mathrm{H}} 2$ allergic airway response to CRA in Myd88 - / - mice. C57BL/6 and Myd88 - / - mice were intranasally treated with or without $50 \mathrm{ng}$ of GM-CSF during sensitization, which was administered along with CRA. Mice were challenged with CRA as usual. (a) BAL differential cell counts were determined by flow cytometry. (b) PAS staining of formalin-fixed and paraffin-embedded lung sections. Original magnification, $\times 10$. (c) Serum CRA-specific IgE levels were determined by ELISA. (d) Number of lung CD4 T cells positive for IL-5, IL-13, IL-17A, or IFN $\gamma$ after restimulation with PMA and ionomycin. Data represent combined data of two independent experiments, mean \pm s.e.m. ( $n=7-11$ mice per group). Comparisons were made using one-way ANOVA with Tukey post hoc test. ${ }^{\star} P<0.05,{ }^{\star \star} P<0.01$.

In contrast, a recent study in HDM showed that TLR4 signaling in both lung epithelial cells and hematopoietic cells contributes to the allergic response. ${ }^{41}$ It is likely that this difference in the contribution of epithelial cells to CRA- versus HDM-driven allergic responses leads to further differences in the induction and requirement of epithelial-derived cytokines.

In this study, we found key differences in the requirement for epithelial-derived cytokines in allergic response to CRA, compared with other allergens. We show that TSLP and IL25 were dispensable for the development of CRA-induced airway inflammation. Although TSLP has been considered a master regulator of Th2 responses, our data indicate a redundant role for TSLP and IL-25 in airway sensitization and is consistent with studies in HDM and peanut allergy. ${ }^{10}$ In addition, IL-33 only had a minor role in allergic responses to CRA; in stark contrast, IL-33 is essential for allergic sensitization to $\mathrm{HDM}^{10,15}$ and many other clinically relevant allergens such as Alternaria alternata, peanut allergen, cypress pollen, and bee venom..$^{10,42-44}$ Although the current paradigm considers TSLP, IL-25, and IL-33 to be critical drivers of Th2 allergic responses, we present a novel pathway in which all three epithelial-derived cytokines are not crucial for sensitization to CRA.

Inhaled allergens and other noxious stimuli such as viruses, cigarette smoke, and diesel exhaust fumes can upregulate the expression of GM-CSF in the airway. ${ }^{45-48}$ Increased levels of GM-CSF amplifies the risk of allergic sensitization by lowering the threshold of allergen required for allergic responses. ${ }^{16}$ In addition, neutralizing GM-CSF at sensitization reduces allergic inflammation to HDM and $B$. tropicalis mite allergen. ${ }^{15,17,18}$ However, in contrast to HDM in which both IL-33 and GM-CSF are required for allergic responses, we found that epithelial-derived GM-CSF was the primary driver of allergic sensitization to CRA. Furthermore, in the absence of MyD88, delivery of exogenous GM-CSF was sufficient to initiate an allergic response to CRA, which suggests that IL-33 is not required for GM-CSFmediated responses to CRA. Interestingly, we also show that GM-CSF selectively initiates the Th2, but not the Th17, arm of the immune response to CRA, which indicates a directed role for GM-CSF that extends beyond a proinflammatory action. 
Although epithelial-derived GM-CSF has an important role in sensitization to both HDM and CRA, there are key differences in the pathways that lead to production of GMCSF by these distinct allergens. Willart et al. ${ }^{15}$ showed that sensitization to HDM is driven by epithelial-derived IL- $1 \alpha$, which acts upstream in the cytokine cascade to initiate the release of GM-CSF in an autocrine manner. However, the requirement for IL- $1 \alpha$ in HDM-driven allergic responses depends the allergen dose and administration protocol. ${ }^{49}$ In contrast, IL- $1 \alpha$ was not upregulated in response to CRA and was not required for allergic responses to CRA, suggesting that GM-CSF production is independent of IL- $1 \alpha$. Despite differences in the pathways of sensitization initiated by CRA versus $\mathrm{HDM}$, these pathways converge on GM-CSF, which suggests a central role for GM-CSF in allergic sensitization.

In conclusion, we have determined the role of epithelialderived cytokines in CRA-driven allergic responses. We uncovered a novel pathway in which epithelial-derived GM-CSF, but not TSLP, IL-25, or IL-33, is essential for allergic sensitization to CRA. Upregulation of GM-CSF in lung epithelial cells occurs through a MyD88-dependent pathway that does not require IL- $1 \alpha$. Downstream of MyD88, GM-CSF selectively initiates a Th2 allergic response, but not Th17mediated responses. Overall, our findings establish a central role for epithelial-derived GM-CSF in allergic sensitization to CRA and suggest that GM-CSF might be an important therapeutic target.

\section{METHODS}

Mice. C57BL/6 mice were purchased from Jackson (Bar Harbor, ME) or Charles River Laboratories (Wilmington, MA). Tlr2 - / - mice were provided by John Gebe (Benaroya Research Institute). Tlr $4^{l p s-d e l}$ mice on the C57BL/6 background were obtained from The Jackson Laboratory; Myd88 - / - mice were provided by Tobias Hohl (Memorial Sloan Kettering Cancer Center); $M y d 88^{\text {flox/flox }}$ mice were provided by Mohamed Oukka (Seattle Children's Hospital); casp 1-I - mice were provided by Michael Gale (University of Washington); Il33 - I - mice were provided by Dirk Smith (Amgen, Seattle, WA); SPC-Cre mice were provided by Brigid Hogan (Duke University); Ill7rb - / - mice were provided by Xiaoxia Li (Cleveland Clinic Lerner Research Institute). TSLPR - / - mice were described previously. ${ }^{50}$ All animals were housed in specific pathogen-free conditions in the Benaroya Research Institute animal facility and all experiments were approved by the Benaroya Research Institute Animal Care and Use Committee.

Reagents. Lyophilized whole body German cockroach extract was purchased from Greer laboratories (XPB46D3A4, Lot \# 259066, Lenoir, NC) and resuspended in phosphate-buffered saline (PBS) to a protein concentration of $2 \mathrm{mg} \mathrm{ml}^{-1}$. Low endotoxin ovalbumin was purchased from Worthington Biochemical Corporation (LS003061, Lakewood, NJ). LPS from E. coli 026:B6 was purchased from Sigma (L2654, St. Louis, MO). Human IL-1ra (anakinra) was purchased from the Virginia Mason hospital pharmacy (Seattle, WA). Recombinant GM-CSF was purchased from Peprotech (315-03, Rocky Hill, NJ).

CRA induced allergic airway model. On days $0-2$, mice were anesthetized with isoflurane and sensitized intranasally with $40 \mu \mathrm{g}$ of CRA (Greer, B46) in a total volume of $20 \mu$ PBS. After 15 days, mice were challenged intranasally with $40 \mu \mathrm{g}$ of CRA on 2 consecutive days and airway inflammation was assessed $72 \mathrm{~h}$ later. Control mice were treated with PBS under the same protocol. For neutralization experiments, anti-GM-CSF antibody (Clone MP1-22E9, Biolegend, San Diego, CA) was injected $5 \mathrm{~h}$ before the first sensitization or challenge dose. In total, $120 \mu \mathrm{g}$ of antibody was administered i.p. and $30 \mu \mathrm{g}$ of antibody was administered intranasally. Anakinra, IL-1ra, was i.p. administered at $25 \mathrm{mg} \mathrm{kg}^{-1}$ with each dose of CRA for a total of five times. To deplete CD4 T cells, $150 \mu \mathrm{g}$ of anti-CD4 antibody (GK1.5, Bio X Cell, West Lebanon, NH) was i.p. administered on days -1, 2, and 16. To determine whether GM-CSF can recover $\mathrm{T}_{\mathrm{H}} 2$ allergic inflammation in Myd88-/ - mice, mice were intranasally treated with $50 \mathrm{ng}$ of GM-CSF plus CRA during sensitization and were only challenged with CRA.

Evaluation of airway inflammation. Mice were euthanized by i.p. injection with $1 \mathrm{ml}$ of $2.5 \%$ Avertin. BAL was performed four times, each time with $1 \mathrm{ml}$ of PBS. Next, BAL was centrifuged at $250 \times g$ for 5 min to collect the cell pellet. Cells were resuspended in FACS (fluorescence-activated cell sorting) buffer and counted using a hemocytometer. Differential cell counts were performed by flow cytometry. The first $\mathrm{ml}$ of BAL fluid collected for enzyme-linked immunosorbent assay (ELISA).

After BAL, lungs were perfused by injecting $3 \mathrm{ml}$ of PBS into the right ventricle of the heart until the lungs turned white. The right upper lobe of the lung was placed in $1 \mathrm{ml}$ of RNALater and stored at $-80^{\circ} \mathrm{C}$ for later analysis by qPCR. The remaining lung tissue was fixed in $10 \%$ neutral buffered formalin. Tissues were embedded in paraffin, sectioned, and stained with hematoxylin and eosin and periodic acid-Schiff. Serum was collected and analyzed for CRA-specific antibodies by ELISA.

To determine differential cell counts in the lung, single cell suspensions were prepared by cutting the lung into fine pieces using a scissor. Next, lung tissue was digested in $50 \mu \mathrm{g} \mathrm{ml}^{-1}$ of Liberase TM (Roche, Indianapolis, IN) and $10 \mathrm{U} \mathrm{ml}^{-1}$ of DNase I (Sigma) in Rosewell Park Memorial Institute RPMI-1640 at $37^{\circ} \mathrm{C}$ for $30 \mathrm{~min}$. Digested lung samples were filtered through a $100-\mu \mathrm{m}$ cell strainer and washed with equal volumes of Rosewell Park Memorial Institute plus $20 \%$ FBS. Red blood cells were lysed with ACK lysis buffer and lung cells were centrifuged at $250 \times \mathrm{g}$ for $5 \mathrm{~min}$. Cells were resuspended in FACS buffer and counted using a hemocytometer. Differential cell counts were performed by flow cytometry. Lung cells were stimulated for $4 \mathrm{~h}$ with PMA ( $50 \mathrm{ng} \mathrm{ml}^{-1}$ ), ionomycin (500 $\mathrm{ng} \mathrm{ml}^{-1}$ ), and GolgiPlug (BD Biosciences, San Jose, CA) at the recommended concentration.

A647-CRA and migration of DCs. A647 was conjugated to CRA using the Alexa Fluor 647 microscale protein labeling kit per manufacturer's instructions (Life Technologies, Carlsbad, CA). DC uptake of A647$\mathrm{CRA}$ and migration to the draining lymph node was assessed by administering $11 \mu \mathrm{g}$ of A647-CRA plus $39 \mu \mathrm{g}$ of unconjugated CRA intranasally. Twenty-four hours later, lung draining lymph node was collected and single cell suspension was prepared. Lymph nodes were teased apart using needles and digested in $1 \mathrm{ml}$ of digest solution containing $50 \mu \mathrm{g} \mathrm{ml}^{-1}$ of Liberase TM (Roche) and $10 \mathrm{U} \mathrm{ml}^{-1}$ of DNase I in Rosewell Park Memorial Institute 1640. After digesting for $25 \mathrm{~min}$ at $37^{\circ} \mathrm{C}, 100 \mu \mathrm{l}$ of $0.1 \mathrm{~m}$ ethylenediaminetetraacetic acid was added to each sample and digested for 5 additional minutes at $37^{\circ} \mathrm{C}$. Next, digested lymph nodes were crushed with a $1 \mathrm{ml}$ syringe and filtered through a $100-\mu \mathrm{m}$ cell filter. Cells were resuspended in FACS buffer and analyzed by flow cytometry.

Evaluation of sensitization to CRA. On days $0-2$, mice were sensitized with $40 \mu \mathrm{g}$ of CRA intranasally. On day 3, lung draining lymph nodes were collected and single-cell suspensions were prepared as described above. Cells were plated in a 96-well flat bottom plate at $5 \times 10^{6}$ cells ml $^{-1}$ and restimulated with 0 or $10 \mu \mathrm{g} \mathrm{ml}^{-1}$ of CRA. The cell culture supernatant was collected on day 7 and cytokine levels were analyzed by ELISA.

BM chimeras. Mice were irradiated twice with $4.5 \mathrm{~Gy}$ and at least $2 \times 10^{6} \mathrm{BM}$ cells were transferred intravaneously by retro-orbital 
injection. Mice were used for experiments after 8-10 weeks to allow for $\mathrm{BM}$ reconstitution.

Flow cytometry. To prevent nonspecific binding of antibodies, cells were incubated with anti-CD16/CD32 (Clone: 2.4G2) in FACS buffer for $15 \mathrm{~min}$ at room temperature. The following antibodies were purchased: anti-Ly6G FITC (1A8), anti-IFN $\gamma$ FITC (XMG1.2), anti-Ly6C PerCpCy5.5 (HK1.4), anti-CD103 Pacific Blue (2E7), anti-Foxp3 e450 (FJK-16s), anti-CD4 BV605 (RM4-5), anti-CD80 BV605 (16-10A1), anti-CD45R BV650 (RA3-6B2), anti-IL-5 APC (TRFK5), anti-MHCII A700 (M5/114.15.2), anti-CD44 A700 (IM7), anti-CD11b APC-e780 (M1/70), anti-TCR $\beta$ APC-e780 (H57-597), anti-Siglec F PE (E50-2440), anti-IL-13 PE (eBIo13A), anti-CD3 PECy5 (145-2C11), anti-CD11c PE-Cy7 (N418), anti-IL-4 PECy7 (BVD6-24G2). Cells were stained with surface antibodies for $12 \mathrm{~min}$ at room temperature. For intracellular staining of cytokines, cells were fixed, permeabilized, and stained using the Foxp3 fix/perm buffer set (Biolegend) according to manufacturer's instructions. Samples were analyzed with BD LSR II flow cytometer (BD Biosciences).

Real-time PCR. Lung tissues were homogenized in RNA lysis buffer and RNA was isolated using the Nucleospin RNA kit (Clontech, Mountain View, CA). RNA was reverse-transcribed into cDNA using PrimeScript Reverse Transcriptase (Takara, Mountain View, CA) according to the manufacturer's instructions. cDNA was amplified in a 7900HT Sequence Detection System (Applied Biosystems, Foster City, CA, USA) using SYBR Premix Ex Taq II (Takara). The following primer pairs were used: $c s f 2$ forward, $5^{\prime}$-GGCTAAGGTCCTGAGG AGGAT-3'; csf 2 reverse, $5^{\prime}$-ACCTCTTCATTCAACGTGA CAGG-3'; Il4 forward, 5'-TCATCGGCATTTTGAACGAG-3'; Il4 reverse, $5^{\prime}$-TTTGGCACATCCA TCTCCG-3'; Il5 forward, 5' -TGCCTGGA GCAGCTGGAT-3'; Il5 reverse, $5^{\prime}$-TGGCTGGCTCTC ATTCAC ACT-3'; Ill 3 forward, $5^{\prime}$-ATTCCCTGACCAACATCTCCAA-3'; Il13 reverse, 5'-CGGTT ACAGAGGCCATGCAA-3'; Ill7a forward, $5^{\prime}$-ATCAGGACGCGCAAACATGAGT-3'; Il17a reverse, 5'-ACGC TGAGCTTTGAGGGATGAT- $3^{\prime}$; Ifng forward, $5^{\prime}$-CCTGCGGCCTA GCTCTGA G-3'; Ifng reverse, 5' -GCCATGAGGAAGAGCTGCA-3'; Gapdh forward, 5'-TCCATGACAACTT TGGCATTG-3'; Gapdh reverse, $5^{\prime}$-CAGTCTTCTGGGTGGCAGTGA-3'.

ALI cultures. Primary airway epithelial cells were cultured as previously described. ${ }^{51}$ Mice were euthanized by $\mathrm{CO}_{2}$ and the trachea was collected and digested in $0.2 \%$ pronase at $4{ }^{\circ} \mathrm{C}$ overnight. Mouse tracheal epithelial cells were isolated and cultured on collagen-coated transwells. After 1 week, mouse tracheal epithelial cells cultures were transitioned to ALI by removing medium from the upper compartment and maintained at ALI for 2 weeks. Cells were exposed to $15 \mu \mathrm{g}$ of CRA for $24 \mathrm{~h}$ and medium from the basal compartment was collected for ELISA.

ELISA. To detect CRA-specific IgE, plates were coated overnight with $6.25 \mu \mathrm{g} \mathrm{ml}^{-1} \mathrm{CRA}$ in PBS at $4{ }^{\circ} \mathrm{C}$. Plates were washed and blocked with $1 \%$ BSA in PBS for $2 \mathrm{~h}$ at room temperature. Serum samples were added to the plates and incubated for $2 \mathrm{~h}$ at room temperature. Plates were washed and biotin-conjugated anti-mouse IgE (R35-118) was added at 1:250 dilution and incubated for $2 \mathrm{~h}$ at room temperature. Plates were washed and incubated with streptavidinHRP for 30 min. 1-Step Ultra TMB-ELISA substrate (Pierce, Rockford, IL) was added and incubated at room temperature in the dark. The reaction was stopped with $2 \mathrm{~N} \mathrm{H}_{2} \mathrm{SO}_{4}$ and $\mathrm{OD}$ was measured at $450 \mathrm{~nm}$.

To detect cytokines, the following capture and detection antibody pairs were used: anti-IL-4 Purified (11B11) and anti-IL-4 Biotin (BVD6-24G2), anti-IL-5 Purified (TRFK5) and anti-IL-5 Biotin (TRFK4), anti-IL-13 Purified (eBio13A) and anti-IL-13 Biotin (eBio1316H), anti-IL-17A Purified (eBio17CK15A5) and anti-IL-17A Biotin (eBio17B7), anti-GM-CSF Purified (MP1-22E9) and anti-GM-
CSF Biotin (MP1-3G6). The concentration of cytokines in the BAL fluid were detected using these antibodies and the protocol described above.

Statistics. Statistical analysis was performed using GraphPad Prism 5. Comparisons were made using either unpaired Student's $t$-test or oneway ANOVA with a Tukey post hoc test. ${ }^{\star} P<0.05$, ${ }^{\star *} P<0.01$, ${ }_{* * *} P<0.001$.

SUPPLEMENTARY MATERIAL is linked to the online version of the paper at http://www.nature.com/mi

\section{ACKNOWLEDGMENTS}

We thank Drs Jessica Hamerman, Daniel Campbell, Florence Roan, and Jen-Feng Lai for critical discussion of the manuscript. The work was supported in part by NIH grants RO1 Al068731 and PO1 HL098067 (S.F.Z). A.S. is supported by the National Science Foundation Graduate Research Fellowship Grant DGE-1256082.

\section{AUTHOR CONTRIBUTION}

A.S., W.C.P., and S.F.Z. designed experiments. A.S. performed all experiments. A.S., W.C.P., and S.F.Z. wrote the manuscript.

\section{DISCLOSURE}

The authors declare no conflict of interest.

c 2017 Society for Mucosal Immunology

\section{REFERENCES}

1. Wenzel, S.E. Asthma phenotypes: the evolution from clinical to molecular approaches. Nat. Med. 18, 716-725 (2012).

2. Lambrecht, B.N. \& Hammad, H. Allergens and the airway epithelium response: gateway to allergic sensitization. J. Allergy Clin. Immunol. 134 499-507 (2014)

3. Saenz, S.a., Taylor, B.C. \& Artis, D. Welcome to the neighborhood: epithelial cell-derived cytokines license innate and adaptive immune responses at mucosal sites. Immunol. Rev. 226, 172-190 (2008).

4. Ziegler, S. \& Artis, D. Sensing the outside world: TSLP regulates barrier immunity. Nat. Immunol. 11, 289-293 (2010).

5. Zhou, B. et al. Thymic stromal lymphopoietin as a key initiator of allergic airway inflammation in mice. Nat. Immunol. 6, 1047-1053 (2005).

6. Schmitz, J. et al. IL-33, an interleukin-1-like cytokine that signals via the IL-1 receptor-related protein ST2 and induces T helper type 2-associated cytokines. Immunity 23, 479-490 (2005).

7. Tamachi, T., Maezawa, Y. \& Ikeda, K. IL-25 enhances allergic airway inflammation by amplifying a TH 2 cell-dependent pathway in mice J. Allergy Clin. Immunol. 118, 606-614 (2006).

8. Stämpfli, M.R. et al. GM-CSF transgene expression in the airway allows aerosolized ovalbumin to induce allergic sensitization in mice. J. Clin. Invest. 102, 1704-1714 (1998).

9. Ashrin, M.N. et al. A critical role for thymic stromal lymphopoietin in nickelinduced allergy in mice. J. Immunol. 192, 4025-4031 (2014).

10. Chu, D.K. et al. IL-33, but not thymic stromal lymphopoietin or IL-25, is central to mite and peanut allergic sensitization. J. Allergy Clin. Immunol. 9, e88714 (2012).

11. Bleck, B. et al. MicroRNA-375 regulation of thymic stromal lymphopoietin by diesel exhaust particles and ambient particulate matter in human bronchial epithelial cells. J. Immunol. 190, 3757-3763 (2013).

12. Kouzaki, H., O'Grady, S.M., Lawrence, C.B. \& Kita, H. Proteases induce production of thymic stromal lymphopoietin by airway epithelial cells through protease-activated receptor-2. J. Immunol. 183, 1427-1434 (2009).

13. Li, D.Q. et al. Short ragweed pollen triggers allergic inflammation through Toll-like receptor 4-dependent thymic stromal lymphopoietin/OX40 ligand/ OX40 signaling pathways. J. Allergy Clin. Immunol. 128, 1318-1325.e2 (2011). 
14. Van Dyken, S.J. et al. Chitin activates parallel immune modules that direct distinct inflammatory responses via innate lymphoid type 2 and $\gamma \delta$ T cells. Immunity 24, 2584-2592 (2014).

15. Willart, M.A.M. et al. Interleukin-1 $\alpha$ controls allergic sensitization to inhaled house dust mite via the epithelial release of GM-CSF and IL-33. J. Exp. Med. 209, 1505-1517 (2012).

16. Llop-Guevara, A. et al. A GM-CSF/L-33 pathway facilitates allergic airway responses to sub-threshold house dust mite exposure. PLoS One $\mathbf{9}$, e88714 (2014).

17. Zhou, Q. et al. GM-CSF-licensed CD11b + lung dendritic cells orchestrate Th2 immunity to blomia tropicalis. J. Immunol. 193, 496-509 (2014).

18. Cates, E., Fattouh, R. \& Wattie, J. Intranasal exposure of mice to house dust mite elicits allergic airway inflammation via a GM-CSF-mediated mechanism. J. Immunol. 173, 6384-6392 (2004).

19. Arruda, L.K. \& Pomés, A. Every Cockroach is Beautiful to Its Mother Int. Arch. Allergy Immunol. 161, 289-292 (2013).

20. Rosenstreich, D.L. et al. The role of cockroach allergy and exposure to cockroach allergen in causing morbidity among inner-city children with asthma. N. Engl. J. Med. 336, 1356-1363 (1997).

21. Eggleston, P.A. et al. Relationship of indoor allergen exposure to skin test sensitivity in inner-city children with asthma. J. Allergy Clin. Immunol. 102, 563-570 (1998).

22. Page, K., Strunk, V.S. \& Hershenson, M.B. Cockroach proteases increase IL-8 expression in human bronchial epithelial cells via activation of protease-activated receptor (PAR)-2 and extracellular-signal-regulated kinase. J. Allergy Clin. Immunol. 112, 1112-1118 (2003).

23. Kim, J.Y. et al. Alveolar macrophages play a key role in cockroach-induced allergic inflammation via TNF- $\alpha$ pathway. PLoS One 7, e47971 (2012).

24. Lee, K.E., Kim, J.W., Jeong, K.Y., Kim, K.E., Yong, T.S. \& Sohn, M.H. Regulation of German cockroach extract-induced IL-8 expression in human airway epithelial cells. Clin. Exp. Allergy 37, 1364-1373 (2007).

25. Page, K. et al. Early immunological response to German cockroach frass exposure induces a Th2/Th17 environment. J. Innate Immun. 3, 167-179 (2011).

26. Jang, S., Morris, S. \& Lukacs, N.W. TSLP promotes induction of Th2 differentiation but is not necessary during established allergen-induced pulmonary disease. PLoS One 8, e56433 (2013).

27. Petersen, B.C., Budelsky, A.L., Baptist, A.P., Schaller, M.A. \& Lukacs, N.W. Interleukin-25 induces type 2 cytokine production in a steroid-resistant interleukin-17RB + myeloid population that exacerbates asthmatic pathology. Nat. Med. 18, 751-758 (2012).

28. Eisenbarth, S.C., Piggott, D.A., Huleatt, J.W., Visintin, I., Herrick, C.A. \& Bottomly, K. Lipopolysaccharide-enhanced, toll-like receptor 4-dependent thelper cell type 2 responses to inhaled antigen. J. Exp. Med. 196, 1645-1651 (2002).

29. Wang, J. et al. Toll-like receptors expressed by dermal fibroblasts contribute to hypertrophic scarring. J. Cell Physiol. 226, 1265-1273 (2011).

30. Okubo, T. \& Hogan, B.L.M. Hyperactive Wnt signaling changes the developmental potential of embryonic lung endoderm. J. Biol. 3, 11 (2004).

31. Okubo, T., Knoepfler, P.S., Eisenman, R.N. \& Hogan, B.L. Nmyc plays an essential role during lung development as a dosage-sensitive regulator of progenitor cell proliferation and differentiation. Development 132, 1363-1374 (2005).

32. Didon, L. et al. Lung epithelial CCAAT/enhancer-binding protein-beta is necessary for the integrity of inflammatory responses to cigarette smoke. Am. J. Respir. Crit. Care Med. 184, 233-242 (2011).

33. Perez-Nazario, N., Rangel-Moreno, J., O’Reilly, M.A., Pasparakis, M., Gigliotti, F. \& Wright, T.W. Selective ablation of lung epithelial IKK2 impairs pulmonary Th17 responses and delays the clearance of Pneumocystis J. Immunol. 191, 4720-4730 (2013).
34. Manzo, N.D., Foster, W.M. \& Stripp, B.R. Amphiregulin-dependent mucous cell metaplasia in a model of nonallergic lung injury. Am. J. Respir. Cell Mol. Biol. 47, 349-357 (2012).

35. Arizmendi, N.G. et al. Mucosal allergic sensitization to cockroach allergens is dependent on proteinase activity and proteinase-activated receptor-2 activation. J. Immunol. 186, 3164-3172 (2011).

36. Day, S.B., Ledford, J.R., Zhou, P., Lewkowich, I.P. \& Page, K. German cockroach proteases and protease-activated receptor-2 regulate chemokine production and dendritic cell recruitment. J. Innate Immun. 4, 100-110 (2012).

37. Mueller, G.a. et al. The novel structure of the cockroach allergen Bla g 1 has implications for allergenicity and exposure assessment. J. Allergy Clin. Immunol. 132, 1420-1426 (2013).

38. Ullah, M.A. et al. Receptor for advanced glycation end products and its ligand high-mobility group box-1 mediate allergic airway sensitization and airway inflammation. J. Allergy Clin. Immunol. 134, 440-450.e3 (2014).

39. Page, K., Lierl, K.M., Hughes, V.S., Zhou, P., Ledford, J.R. \& Wills-Karp, M. TLR2-mediated activation of neutrophils in response to German cockroach frass. J. Immunol. 180, 6317-6324 (2008).

40. Page, K., Ledford, J.R., Zhou, P. \& Wills-Karp, M. A TLR2 agonist in German cockroach frass activates MMP-9 release and is protective against allergic inflammation in mice. J. Immunol. 183, 3400-3408 (2009).

41. McAlees, J.W. et al. Distinct Trr4-expressing cell compartments control neutrophilic and eosinophilic airway inflammation. Mucosal Immunol. 8, 863-873 (2015).

42. Snelgrove, R.J. et al. Alternaria-derived serine protease activity drives IL-33-mediated asthma exacerbations. J. Allergy Clin. Immunol. 134, 583-592.e6 (2014).

43. Palm, N.W., Rosenstein, R.K., Yu, S., Schenten, D.D., Florsheim, E. \& Medzhitov, R. Bee venom phospholipase A2 induces a primary type 2 response that is dependent on the receptor ST2 and confers protective immunity. Immunity 39, 976-985 (2013).

44. Gabriele, L. et al. Novel allergic asthma model demonstrates ST2dependent dendritic cell targeting by cypress pollen. J. Allergy Clin. Immunol. 132, 686-695 (2013).

45. Subauste MCEA. Infection of a HUman respiratory epithelial cell line with rhinovirus-Induction of cytokine release and modulation of susceptibility to infection by cytokine exposure. Am. Soc. Clin. Investig. 96, 549-557 (1995).

46. Schelenz, S., Smith, D.A. \& Bancroft, G.J. Cytokine and chemokine responses following pulmonary challenge with Aspergillus fumigatus: obligatory role of TNF-alpha and GM-CSF in neutrophil recruitment. Med. Mycol. 37, 183-194 (1999).

47. Ohta, K. et al. Diesel exhaust particulate induces airway hyperresponsiveness in a murine model: Essential role of GM-CSF. J. Allergy Clin. Immunol. 104, 1024-1030 (1999).

48. Trimble, N.J., Botelho, F.M., Bauer, C.M.T., Fattouh, R. \& Stämpfli, M.R. Adjuvant and anti-inflammatory properties of cigarette smoke in murine allergic airway inflammation. Am. J. Respir. Cell Mol. Biol. 40, 38-46 (2009).

49. Nikota, J.K. et al. Differential expression and function of breast regression protein 39 (BRP-39) in murine models of subacute cigarette smoke exposure and allergic airway inflammation. Respir. Res. 12, 12 (2011).

50. Carpino, N. \& Thierfelder, W. Absence of an essential role for thymic stromal lymphopoietin receptor in murine B-cell development. Mol. Cell Biol. 24, 2584-2592 (2004).

51. You, Y., Richer, E.J., Huang, T. \& Brody, S.L. Growth and differentiation of mouse tracheal epithelial cells: selection of a proliferative population. Am. J. Physiol. Lung Cell Mol. Physiol. 283, L1315-L1321 (2002). 